\title{
In vitro Effect of Bisphosphonates on Squamous Cell Carcinoma from Tongue Tissue
}

\author{
OCTAVIA IULIA BALEAN ${ }^{1 *}$, ATENA GALUSCAN ${ }^{1}$, DANIELA J UMANCA ${ }^{1}$, CLAUDIA FARCAS², DORINA CORICOVAC ${ }^{2}$, \\ DOINA CHIORAN ${ }^{3}$, VOICHITA LAZUREANU4*, ANGELA CODRUTA PODARIU ${ }^{1}$ \\ ${ }^{1}$ University of Medicine and Pharmacy Victor Babes, Faculty of Dental Medicine, Department I, 14A Splaiul Tudor \\ Vladimirescu, 300173, Timisoara, Romania \\ 2 Victor Babes University of Medicine and Pharmacy, Faculty of Pharmacy, 2 Eftimie Murgu Sq, 300041, Timisoara, Romania \\ ${ }^{3}$ University of Medicine and Pharmacy Victor Babes, Faculty of Dental Medicine, Department II, 5 Take lonescu, 300062, \\ Timisoara, Romania \\ ${ }^{4}$ University of Medicine and Pharmacy Victor Babes, Faculty of Medicine, 2 Eftimie Murgu Sq, 300041, Timisoara, Romania
}

\begin{abstract}
The purpose of this in vitro study was to evaluate the efficacy of three different types of bisphosphonates: Actonel (risedronate sodium), Fosamax (alendronic acid) and Ossica (ibandronic acid) on a squamous carcinoma cell line (SCC-4) with tongue tissue origin. The cell viability was assessed after a stimulation period of $24 \mathrm{~h}$ and the Alamar Blue test was performed. The assessmentrevealed that the viability of squamous cell carcinoma was slightly reduced after treatment with the smallest concentration of bisphosphonates, with a lowest rate (89\%) recorded for Actonel. When a concentration of 2 and $2.5 \mu \mathrm{M}$ was used, the cell viability was between $85-89 \%$ independently of the type of bisphosphonates used. The higher concentrations of $3 \mu \mathrm{M}, 4 \mu \mathrm{M}$ showed a significant reduction of $72 \%$ when using Fosamax, and $68 \%$ when using Ossica. We can state that the viability of tongue squamous cell carcinoma cells decreases as the concentration of bisphosphonates used increases.
\end{abstract}

Key words: bisphosphonates, tongue squamous cell carcinoma, cell viability

Bisphosphonates have long become an integral part of therapy in benign and malignant metabolic bone diseases, such as Paget's disease, osteoporosis and tumourassociated hypercalcaemia and osteolysis, because of their ability to inhibit bone loss. Bisphosphonates are analogues of the naturally occurring inorganic pyrophosphate (PPi) in which the phosphoanhydride linkage (P-O-P) has been replaced by a non-hydrolysable P-C-P bond. Two covalently bound side chains (referred to as R1 and R2) at the central carbon atom give rise to a great variety of possible structures and contribute to their different relative potencies. Like their natural analogue, bisphosphonates are capable of binding divalent cations like $\mathrm{Ca}^{2+}$ in a tridentate manner, by coordination of the two phosphonate groups and the R1 substituent (preferably a hydroxyl group) [1-3].<smiles>O=P(O)(O)OP(=O)(O)O</smiles>

pyrophosphate (PPi)

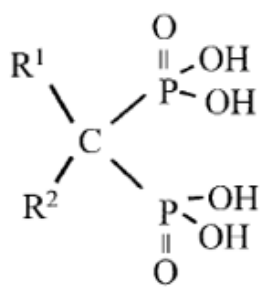

bisphosphonate [3]
The ability to chelate $\mathrm{Ca}^{2+}$ ions is the basis for the bonetargeting property of bisphosphonates, whereas the structure and stereochemistry of the R2 chain determines their efficacy to inhibit the activity of bone-resorbing cells (osteoclasts), leading to inhibition of bone resorption. Bisphosphonates can be grouped into two classes according to their mechanisms of action. Those with a simple R2 side chain lacking a nitrogen-containing functional group (such as clodronate) are metabolised intracellularly into non-hydrolysable ATP analogues that accumulate in the cytosol and subsequently induce apoptosis [1,2]. Nitrogen-containing bisphosphonates (NBPs; such as pamidronate, risedronate or zoledronate), which are several orders of magnitude more potent in inhibiting bone resorption than their non-nitrogen counterparts, act on the mevalonate pathway by inhibiting the key enzyme farnesyl diphosphate synthase (FPP synthase), thereby depleting the cell of the isoprenoid lipids FPP and geranylgeranyl diphosphate (GGPP) [2,4].

Bisphosphonates represent a group of pharmacological agents that inhibit bone resorption, their main antiosteolytic and antiangiogenic effects leading to their clinical applicability in various diseases. Currently, oral bisphosphonates are widely used in the treatment of bone metastatic disease (following malignant breast, prostate, lung or kidney tumours) or primary bone osteolytic pathology (multiple myeloma, Paget bone disease) or to alleviate the effects of hypercalcaemia in malignant diseases and pain associated with the osteolytic bone pathology [5].

The cumulative cytotoxicity of simple bisphosphonates inhibits bone resorption through osteoclast apoptosis. As bone resorption inhibitors, bisphosphonates have become the standard of care in the treatment of patients with bone metastases, however, it is now clear that bisphosphonates also have a both direct and indirect antitumour effect, this being demonstrated preclinically $[2,6,7]$

Bisphosphonates have demonstrated anticancer activity in vitro against a wide variety of tumour cell lines. The potency of several bisphosphonates to inhibit cancer cell proliferation and increase their apoptosis has been demonstrated in breast, prostate, ovarian, bladder, hepatic cancer, osteosarcoma, leukaemia, melanoma and myeloma cells [2]. Numerous studies have also described the ability of bisphosphonates to inhibitcancer cell invasion in vitro at micromolar concentrations $[2,6,8,9]$. However, the mechanism by which N-BPs induce apoptosis may

* email: balean.octavia@umftr: Phone: +40 748677191; Vlazureanu@yahoo.com 
vary depending on the type of cells and/or bisphosphonate used [10].

Studies reveal that bisphosphonates can act synergistically in combination with a variety of agents, resulting in improved cytotoxic activity in many different types of cancer cells. The use of drug combinations in cancer therapy has been established on the principle that these drugs may act synergistically (provide a greater benefit, in combination, compared to individual ones). There is preclinical evidence that the combination of bisphosphonates with chemotherapy drugs can lead to an improved antitumour treatment [2].

Oral bisphosphonates are widely used in the treatment of osteoporosis, and intravenous bisphosphonates are used in the treatment of bone metastatic disease or primary bone osteolytic pathology, or to alleviate the effects of hypercalcemia in malignant diseases and pain associated with the osteolytic bone pathology [5].

\section{Experimental part}

Materials and methods

Reagents and cell line

AlamarBlue - resazurin sodium salt and dimethyl sulfoxide (DMSO) reagents were provided by SigmaAldrich (Munich, Germany). All reagents were of analytical purity grade.

The cell line used in the present study, squamous cell carcinoma from tongue tissue - SCC-4 cell line (code no, ATCC CRL-1624) was acquired from American Type Culture Collection (ATCC) as frozen vial and stored in standard conditions (liquid nitrogen vapour phase).

\section{Cell culture}

SCC-4 cell line was cultured in specific growth medium: 1:1 mixture of Dulbecco's Modified Eagle's Medium and Ham's F12 medium with L-Glutamine and HEPES (DMEM:F12, code no ATCC 30-2006) provided by ATCC. To obtain a complete growth medium the base medium was supplemented with the following components: $400 \mathrm{ng} / \mathrm{mL}$ hydrocortisone commercially available, $10 \% \mathrm{FCS}$ (fetal calf serum) and $1 \%$ antibiotics mixture of $0.1 \mathrm{mg} / \mathrm{mL}$ streptomycin, $100 \mathrm{lU} / \mathrm{mL}$ penicillin (Sigma-Aldrich; Munich, Germany) to avoid a possible bacterial/fungal contamination during cell culturing.

Cell cultures were maintained under standard conditions, in humidified atmosphere with $5 \% \mathrm{CO}_{2}$ and a constant temperature of $37^{\circ} \mathrm{C}$, in a Steri-Cycle i160 incubator (Thermo Fisher Scientific, USA).

\section{Cell viability assessment}

Alamar Blue (AB) assay is a well-known technique employed for cell viability assessment. The principle of this technique is based on a colorimetric reaction in which the dark blue resazurin salt is converted to resorufin, a pink compound, by the mitochondrial reductase of the viable cells. The optical density of the samples is directly proportional with the viable cell population.

In brief, $1 \times 10^{4}$ cells/well were seeded onto 96-well plate, overnight. The following day, the medium from each well was replaced with a fresh one containing the test compounds to five different concentrations $(1.5,2,2.5,3$, $4 \mu \mathrm{M})$ and the cells were incubated for $24 \mathrm{~h}$. Each concentration was tested in triplicate wells, as well the control cells (no stimulation -cells treated with growth medium). Upon completion of the stimulation period, $20 \mu \mathrm{L} /$ well of $A B$ was added and after $4 \mathrm{~h}$, the mitochondrial reduction of the resazurin to resorufin was determined spectrophotometrically by measuring the absorbance of the wells at a wavelength of $570 \mathrm{~nm}$ and a reference wavelength of $600 \mathrm{~nm}$, with a microplate reader (XMark'MMicroplate, Biorad). The w ells withoutcells were used as negative control.

\section{Cell morphology assessment}

The cells were cultured in 6-well plates to an initial density of $1 \times 10^{6}$ cells/well. When the optimal confluence (85-90\%) was reached the old medium was replaced by a new one containing the test compounds at different concentrations $(1.5,2,2.5,3,4 \mu \mathrm{M})$ and incubated for $24 \mathrm{~h}$. At the end of the incubation period the cells were photographed with an inverted microscope equipped with DP74 integrated camera (Olympus IX73, Tokyo, Japan) in order to observe the possible morphological alterations that could have occurred after the stimulation period had ended. The images were taken at magnification 20X.

\section{Results and discussions}

\section{Cell viability assessment}

In order to evaluate the influence of three differenttypes of bisphosphonates (Actonel, Fosamax, Ossica) on squamous carcinoma SCC-4 cells' viability after a stimulation period of $24 \mathrm{~h}$, the $A B$ test was performed.

As presented in figure 1 , the viability percentage of squamous carcinoma - SCC-4 cells was slightly reduced after $24 \mathrm{~h}$ treatment with bisphosphonates (Actonel, Fosamax, Ossica) at concentration of $1.5 \mu \mathrm{M}$. Actonel induced the lowest proliferation rate, with a viability percentage of 89. However, stimulation with concentrations of 2 and $2.5 \mu \mathrm{M}$ manifested almost the same activity on SCC-4 cell viability, the proliferation rate raging between $85-89 \%$, independently to the bisphosphonate structure. Nevertheless, higher concentrations of bisphosphonates ( 3 and $4 \mu \mathrm{M}$ ) expressed a significant reduction of the squamous carcinoma SCC-4 cell viability, more intense after treatment with Fosamax and Ossica, representing a viability rate of 72 and $68 \%$, respectively, in the case of the highest concentration $(4 \mathrm{mM})$. The solvent used to obtain bisphosphonates stock solution was DMSO and it was also tested for the possibility of inducing cytotoxic effect on SCC-4 cells. The results revealed only a slight inhibitory effect in the case of high concentrations $(3,4 \mu \mathrm{M})$, showing a viability rate of $88.92 \%$ and $88.79 \%$, respectively.

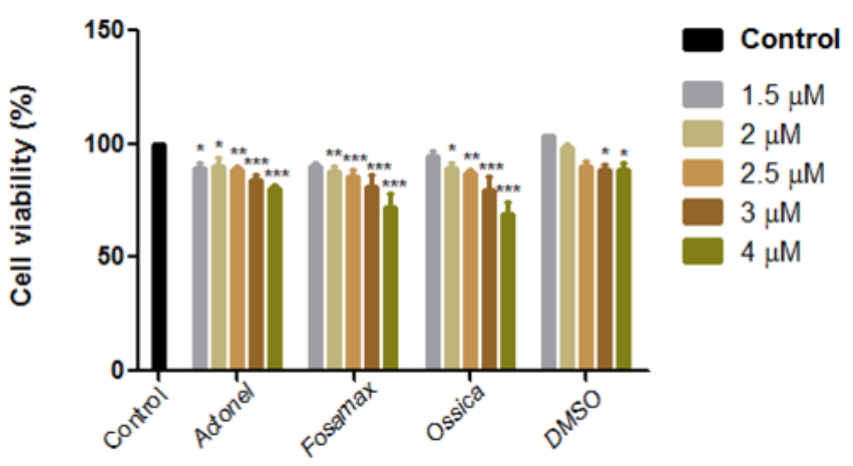

Fig. 1. Squamous cell carcinoma (SCC-4) viability rate, after treatment with different concentrations of bisphosphonates (Actonel, Fosamax, Ossica) for $24 \mathrm{~h}$. The data are expressed as cell viability percentage (\%) normalised to control cells (no stimulation). The results represent the mean values \pm SD of three independent experiments. One-way ANOVA analysis was employed to determine the statistical differences followed by Tukey's posttest ( $*<<0.05 ; * * p<0.01 ; * * * p<0.001$ vs. Control) 
Actonel

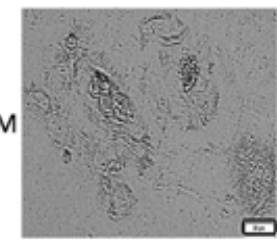

$2 \mu \mathrm{M}$
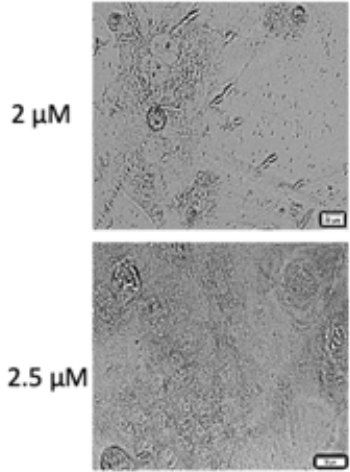

$3 \mu \mathrm{M}$

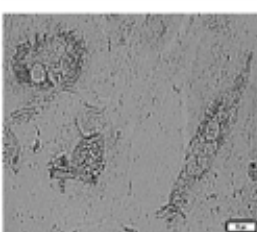

$4 \mu \mathrm{M}$

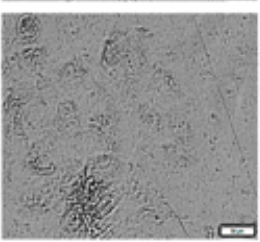

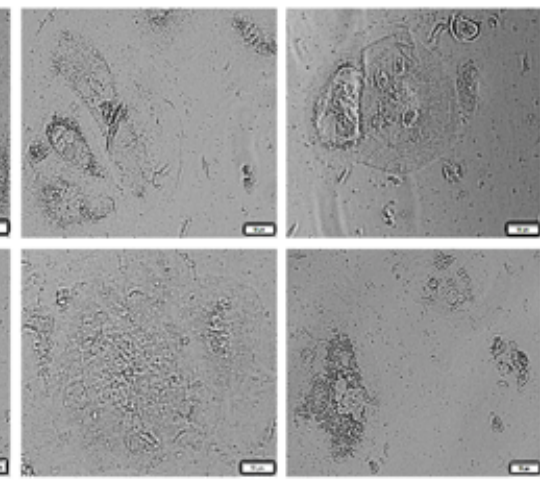
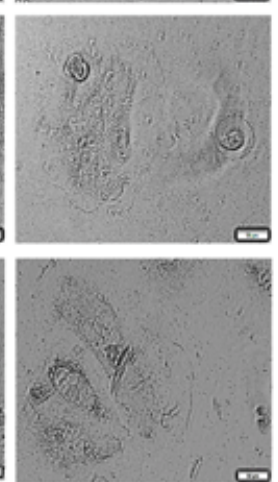

Ossica
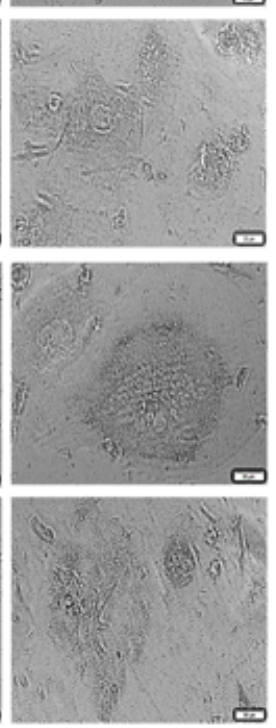

Morpnologic aspects

Pictures of squamous cell carcinoma treated with bisphosphonates (Actonel, Fosamax, Ossica) at different concentrations $(1.5,2,2.5,3,4 \mu \mathrm{M})$ were taken after $24 \mathrm{~h}$ post-stimulation, in order to assess the effect of test compounds on SCC-4 cell morphology. The results are presented in figure 2 .

According to the pictures displayed in figure 2, the morphology of control cells (no stimulation) presented epithelial-like characteristics, forming colonies and an adherent cell culture. After stimulation, the morphological characteristics of the cells were slightly affected by the treatment with the lowest concentration $(1.5 \mu \mathrm{M})$ of bisphosphonates, however some morphological changes appeared when the concentration was increased, the cells manifesting irregular shape. Moreover, the cells stimulated with the highest concentration of bisphosphonates $(4 \mu \mathrm{M})$ suffered major morphological alterations, displaying cell shrinkage. The results described for cell morphology evaluation are sustained by the ones obtained in the cell viability assessment, making our data consistent.

The innovation of this study refers to the use of squamous cell carcinoma from tongue tissue, and the use as stimulants of three types of bisphosphonates: Actonel (risedronate sodium), Fosamax (alendronic acid) and Ossica (ibandronic acid).

Four micromolar concentrations were used in the study. The results obtained showed that as the micromolar concentration increased, the viability of tongue squamous cell carcinoma cells decreased. An increased micromolecular concentration of bisphosphonates was inversely proportional to cell viability. It should be noted that the three types of bisphosphonates used can be given either by injection in the case of Ossica, and orally in the case of Fossamax and Actonel.

Fig. 2. Morphologic aspects of SCC-4 cells after $24 \mathrm{~h}$ post-stimulation with different concentrations of bisphosphonates (Actonel, Fosamax, Ossica). Scale bars represent $50 \mu \mathrm{m}$

Control

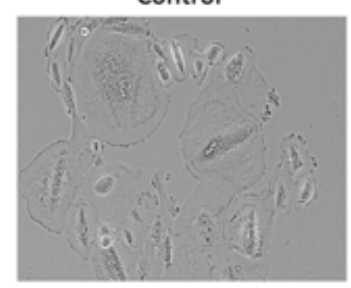

Kruger reported that low concentrations of Fosamax, from $5 \mu \mathrm{M}$ to $20 \mu \mathrm{M}$, improved osteoblast proliferation, and at $100 \mu \mathrm{M}$ concentrations it decreased osteoblast proliferation. [20] In the current study, the administration of Fosamax to tongue squamous cell carcinoma cells at low concentrations decreased less the viability compared to higher concentrations.

It is reported in the literature that osteosarcoma cells showed an increase in proliferation at low doses of bisphosphonates, while inhibition was observed at high doses, the same effect observed in this study for tongue squamous cell carcinoma cells [11].

In vitro, bisphosphonates containing nitrogen in their molecule inhibit the proliferation of osteoblasts having a direct and pro-apoptotic cytostatic action on tumour cells, as is also seen in this study [12].

The purpose of this study is to investigate the antitumour effect of bisphosphonates on tongue squamous cell carcinoma cells, but also to compare Actonel, Fosamax and Ossica, the three substances being used at different concentrations.

\section{Conclusions}

The viability of tongue squamous cell carcinoma cells decreases as the concentration of bisphosphonates used increases.

The results obtained showed a classification of the efficiency of the bisphosphonates used. The highest rate of cell viability decrease was due to the use of Ossica, followed by Fosamax and Alendronat.

In conclusion, we can say that bisphosphonates may have an in vitro antitumor action on tongue squamous cell carcinoma cell. 


\section{References}

1.M. J. ROGERS, J. C.CROCKETT, F. P.COXON, Jukka Mönkkönen Biochemical and molecular mechanisms of action of bisphosphonates, Bone Volume 49, Issue 1, July 2011, Pages 34-41 2.V. STRESING , F. DAUBINE', ISMAHE'NE BENZAID, HANNU MONKKONEN, P. Clezardin Bisphosphonates in cancer terapy Cancer letters Vol.257, Issue 1, 8 November 2007, 16-35

3.R . GRAHAM G., Russell Bisphosphonates: The first 40 years, Bone Volume 49, Issue 1, July 2011, Pages 2-19

4.H. L. NEVILLE-WEBBE, M. GNANT, R. E. Colema Potential AnticancerProperties of Bisphosphonates Seminars in Oncology Volume 37, Supplement 1, J une 2010, Pages S53-S65

5.TRANDAFIR D. TRANDAFIR V. Osteonecroza maxilarelor indusã de bifosfonap: Revista literaturii J urnalul de chirurgie (lasi), 2012, Vol 8 Nr.2 118-128

6. CLEZARDIN P., Potential Anticancer Properties of Bisphosphonates: Insights From Preclinical Studies Anti-Cancer Agents in Medicinal Chemistry (Formerly Current Medicinal Chemistry - Anti-Cancer Agents), Volume 12, Number 2, February 2012, pp. 102-113(12)
7.BROWN H. K.; HOLEN, I. ,Anti-Tumour Effects of Bisphosphonates - What have we Learned from In Vivo Models? Current Cancer Drug Targets, Volume 9, Number 7, November 2009, pp. 807-823(17) 8.P. CLEZARDIN, Bisphosphonates' antitumor activity: An unravelled side of a multifaceted drug class Bone Volume 48, Issue 1, 1 January 2011, Pages 71-79

9.BERENSON J. R. Antitumor effects of bisphosphonates: from the laboratory to the clinic Current Opinion in Supportive and Palliative Care: September 2011 - Volume 5 - Issue 3 - p 233-240

10.M. GNANT, P. Clézardin Direct and indirect anticancer activity of bisphosphonates: A brief review of published literature Cancer Treatment Reviews Volume 38, Issue 5, August 2012, Pages 407-415 11.ACIL Y, ARNDT ML, GULSES A, WIEKER H, NAUJ OKAT H, AYNA M, WILTFANG J, Cytotoxic and inflammatory effects of alendronate and zolendronate on human osteoblasts, gingival fibroblasts and osteosarcoma cells J ournal of Cranio-Maxillofacial Surgery (2018), doi: 10.1016/j.jcms.2017.12.015.

12.CLEZARDIN P. Bisphosphonates antitumor activity: an unravelled side of a multifaceted drug class. Bone 2011 48:71-79

Manuscript received: 5.10 .2018 